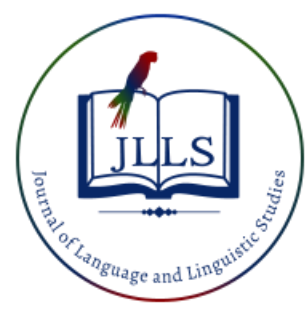

Available online at www.jlls.org

JOURNAL OF LANGUAGE

AND LINGUISTIC STUDIES

ISSN: 1305-578X

Journal of Language and Linguistic Studies, 17(1), 281-300; 2021

\title{
Impact of a systemic functional linguistic informed course on teacher candidates' knowledge about genre and language
}

\author{
Güliz Turgut Dost a 1 iD \\ ${ }^{a}$ Aydin Adnan Menderes University, Aydin, Turkey
}

\begin{abstract}
APA Citation:
Turgut Dost, G. (2021). Impact of a systemic functional linguistic informed course on teacher candidates' knowledge about genre and language. Journal of Language and Linguistic Studies, 17(1), 281-300. Doi: 10.52462/jlls.17

Submission Date: 19/01/2021

Acceptance Date: 13/03/2021
\end{abstract}

\begin{abstract}
This qualitative single-case study examined the impact of a course informed by Systemic Functional Linguistics (SFL) on teacher candidates' knowledge about genre and language. The study was conducted with nineteen teacher candidates and lasted one semester. Data collected through analysis of two texts: a published children's book and a student text written by a fourth-grade bilingual student, both written in a fictional narrative genre. Texts were given at the beginning and end of the course. Data were analyzed through a rubric developed by the course instructor based on the SFL theory. In the rubric, twenty SFL areas regarding language and genre were created and participant comments falling under the proper area were noted on the rubric. Table of frequencies and graphs were created to present the data. Participants' original responses were also given to provide a meaningful context for the findings. Overall results indicated that although participants did not use metalanguage to the fullest potential, they were able to identify the language and genre-related items with higher frequency in both texts at the end of the course. Furthermore, at the beginning of the course, participants considered the published text as having the function of giving information to a reader and teaching how to respond to literature. However, after the course participants began to use it as a model to teach how to write genre- and languagespecific information. Finally, analysis of student text indicated that after the course participants learned to see the issues of children's writing beyond mechanics.
\end{abstract}

Keywords: writing; Systemic Functional Linguistics (SFL); genre; fictional narrative; teacher candidates; teacher education; English Language Learners (ELLs); case study; elementary school

\section{Introduction}

It is no longer surprising for educators to have large numbers of English Language Learners (ELLs) in classrooms and considering that 40 percent of the student population in the U.S. is projected to be ELLs in 2030 (Herrera \& Murry, 2005), it is extremely important to democratize schools by providing quality education to ELLs (Schleppegrell, 2004). Despite all the attention given to and repetitive statements made about providing quality education to ELLs and supporting them, the achievement gap

\footnotetext{
${ }^{1}$ Corresponding author.

E-mail address: guliz.turgut@ adu.edu.tr
} 
between ELLs and non-ELL students persists (Goldenberg, 2008). The lack of instructional focus on academic language has been suggested as the source of the achievement disparities (Aguirre-Muñoz, Park, Amabisca, \& Boscardin, 2008). Therefore, teachers focused on teaching academic language to their ELLs in content areas. However, besides learning the academic language required to be successful in schools, ELLs also need support with learning academic writing because proficiency in an academic language is displayed through academic writing in in-school and out-of-school environments.

Academic writing is difficult for ELLs because they struggle to communicate their message effectively through academic language, which requires a language different from daily-life language. Unlike daily-life language, which is typically verbal, informal, and interactive, academic language uses abstract vocabulary and more formal, specialized, and complex grammatical structures (Christie, 1999; Halliday, 1994; Kress, 1989; Martin \& Veel, 1998; Schleppegrell, 2004). As children move to upper grades, they are expected to use academic language in greater variety, complexity, and length in their writing (Martin \& Rothery, 1986). Additionally, coming from different cultural and linguistic backgrounds, the writing systems ELLs are familiar with in their native language may differ from the academic writing system of the target language (Scott, 2015; Siepmann, 2006; Yang \& Cahill, 2008).

Teaching writing has not been successful with ELLs (Rose \& Martin, 2012) and teachers often struggle to respond in specific ways that are helpful for their ELLs' writing needs (Schleppegrell \& Go, 2007). Teachers without a basic understanding of how language works and how language features change in different contexts can misjudge their students' writing skills (Martin \& Rothery, 1986). Even though national standards already call for attention to language structures and forms in writing instruction, teachers are given little guidance about how to teach writing in ways that enable students to expand their control of language (Schleppegrell, 2004; Schleppegrell \& Go, 2007). The persistent achievement gap between ELLs and non-ELLs and cultural differences in writing systems call for a new approach for writing instruction that would teach ELLs not only the academic language but also the cultural and linguistic intricacies embedded in the American academic writing system. An approach that could help teachers with writing instruction is Systemic Functional Linguistics (SFL).

In this study, throughout a graduate-level course, teacher candidates learned about Systemic Functional Linguistic (SFL) and in the light of SFL, they studied various genres, their structural and linguistic features as well as how to teach writing them in elementary grades. The purpose of this qualitative single-case study was to investigate how teacher candidates' knowledge about genre and language has changed after taking this SFL-informed course on writing. The study inquired the following questions;

1. What genre and linguistic features do teacher candidates identify when analyzing a K-5 published-text before and after the course?

2. What genre and linguistic features do teacher candidates identify when analyzing a K-5 bilingual student's sample writing before and after the course?

After explaining SFL as the conceptual framework of the study and the attributes of the fictional narrative genre featured in this study, the article describes the methods used and presents the results in two sections: one concerning published text and the second to the student text. The discussion argues that a course on writing instruction informed by SFL can change teacher candidates' awareness of fictional narrative genre and the specific language features it requires. Although the course was only one semester-long, the study adds to the extant literature on SFL genre pedagogy's impact on teacher preparation for teaching writing. 


\subsection{Systemic Functional Linguistics (SFL) and genre}

SFL is founded by Michael Halliday (1978) and considers language as dynamic and evolving based on the context and social purposes it is used, rather than being fixed and following pre-determined rules (Derewianka, 1990). "The writing practices of a culture are characterized by recurrent forms of texts used for specific purposes, each characterized by specific discourse organization and language features" (Brisk, Tian, \& Ballard, 2021, p. 2). These recurrent configurations of language to make meaning and to achieve a specific social purpose are called genre (Martin \& Rose, 2008). Each genre has a different purpose, which is achieved through the stages or text structure (Brisk et al., 2021). "Genres informed by SFL theory also focus on language choices as defined by the register, which includes three variables: field, tenor, and mode." (Brisk et al., 2021, p. 2). The field comes from units of meaning expressed in clauses, verb groups, noun groups, adjectives, and adverbials to name a few, and expresses what is spoken or written about. The tenor is the relationship between speaker or writer and audience. An author chooses his/her language and its features depending on the intended audience as well as the writer's voice or identity. In mode, writers use language resources, such as reference ties, lexical ties, and rhetorical links, to create a cohesive text. The language choices a writer makes vary based on whether the text is written, oral, or multimodal. Field, tenor, and mode correspond to three language metafunctions: experiential, interpersonal, and textual (Halliday \& Matthiessen, 2004).

Teachers using SFL as a pedagogical tool teach the linguistic structures of academic language and the features of different genres explicitly (Gibbons, 2002, 2003). SFL can enrich teachers' understanding of key language-based instructional issues. It can also offer teachers a means for focusing explicitly on language and understanding how language construes knowledge (Schleppegrell, 2004). SFL can help teachers support the academic writing development of students by recognizing their strengths and weakness in writing, designing their writing instruction goals and objectives based on students' needs, and providing genre- and language-specific feedback to students (Schleppegrell \& Go, 2007). As teachers become more aware of the linguistic features of the language and different genres required in schools, they can evaluate the language demands students are required to read or write in school (Aguirre-Muñoz et al., 2008).

\subsection{Fictional narrative}

The most common genres students in elementary grades are exposed to include recounts, fictional narratives, procedures, reports, and expositions (Brisk, 2015). In this study, data were collected through two texts, both written in fictional narrative genre. Fictional narratives are imaginative and entertaining stories that teach cultural values (Martin \& Rose, 2008; Roser, Martinez, Fuhrken, \& McDonnold, 2007). The story starts with normal events which are disrupted by some complications and a crisis while they are resolved at the end of the story (Brisk, 2015). The characters are a central element of fictional narratives. In narratives, there are major and minor characters. The major characters drive the story and hold the reader's interest (Brisk, 2015). These characters need to be well developed to justify their goals, problems, and challenges, and how they end up resolving their problems (Brisk, 2015). Most stories have one principal character, but there is also at least a second important character. There can be many minor characters that do not need as much development as the main character (Rog \& Kropp, 2004). Characters have external (age, gender, ethnicity, and physical features) and internal features (traits, interests, abilities, values, feelings, goals or motives, and changes over the course of the story) (Brisk, 2015).

Stages of a fictional narrative include title, orientation, the sequence of events with problem or complication and crisis, evaluation, resolution, and conclusion (Labov \& Waletsky, 1967; Martin \& Rose, 2008). The title usually gives a sense of the topic and may include features that make the story 
sound exciting. The orientation introduces the central characters and other characters, and when and where the story begins (Brisk, 2015). The sequence of events includes the problems and challenges the character faces, building to a crisis, and followed by a resolution. The conclusion of a fictional narrative reveals a lesson learned or changes in the characters from the experience (Brisk, 2015). Narratives may conclude in different ways based on the type of narrative or author choices, such as ending with a moral, a quotation from a character, the main character's feelings about what happened, a summary statement, while legends end with the impact on the present (Brisk, 2015).

Although children usually enter school with the familiarity of the characteristics and structure of fictional narratives, it is challenging for children to write due to the difficulties in the development of characters, taking a third-person point of view, creating a problem and a crisis, tracking the number of participants through narrative and dialogue, and building suspense through language and rhetorical devices (McKenough, 2013; Roser et al., 2007). Starting to write fictional narratives by firstly creating and describing the external and internal features of main characters is important because characters drive the plot in stories (Rog \& Kropp, 2004). With early grades, it is best to focus on students' ability to use the past tense and to tell stories in the third person (Brisk, 2015). Beginning in the $3^{\text {rd }}$ grade, dialogue use can be introduced. By $4^{\text {th }}$ and $5^{\text {th }}$ grade, students should be taught how to add tension and how to add information to create an image of the time, place, and cultural background of characters (Brisk, 2015).

This article contributes to understanding how a semester-long course informed by SFL impacts teacher candidates' knowledge about genre and language. Regarding the results of the published text, this study demonstrated that participants began to use the children's book as a model of a well-written fictional narrative to show students how to write that genre, rather than as a source to respond to literature. Furthermore, regarding the results of the student text, this study demonstrated that participants became more focused on identifying and correcting language errors that interrupted meaning and comprehension, rather than surface level errors, such as punctuation and contractions.

\section{Method}

This study was designed as a qualitative, single-case study because "by concentrating on a single phenomenon or entity, the researcher aims to uncover the interaction of significant factors characteristic of the phenomenon. The case study focuses on holistic description and explanation" (Merriam, 1998, p. 29). The examined single-case was the change in participants' knowledge in language and genre after taking an SFL-informed course. Qualitative case studies can have three main types based on their purposes; exploratory, descriptive, and explanatory studies (Yin, 2014). This study had exploratory purposes as it investigated a situation in which little theory is available or when the measurement is unclear (Yin, 2014). There were two units of analysis, participants' responses to published-text and student-text. These units of analysis were used to answer the research questions.

\subsection{Participants and research setting}

Participants were conveniently sampled teacher candidates registered to a graduate-level Teaching Language Arts course at a private urban university in the USA. Convenience sampling is "based on time, money, location, and availability of sites or respondents" (Merriam, 1998, p. 63). Before the study, a professor was preparing to offer a course informed by SFL theory and incorporated the theory into writing instruction for elementary grades. After taking the approval of the IRB and the course instructor, the study was conducted. Twenty-two (out of twenty-six) teacher candidates agreed to participate in the study by signing the consent forms. Three participants were excluded from the study since they were absent during the completion of some research-related tasks. A total of nineteen 
teacher candidates majoring in elementary education participated in the study. Participants completed a background information form given at the beginning of the course to collect information on the courses they had taken. Table 1 illustrates the number of courses participants had taken on English Language Arts and Sheltered English Instruction. Information about how many of these courses participants had taken was important to understand their familiarity with the language and its instruction because these courses deal with issues of language and how language can be incorporated into instruction.

Table 1. The number of English Language Arts (ELA) and Sheltered English Instruction (SEI) participants had taken before the study

\begin{tabular}{|c|c|c|c|}
\hline Number of Courses & $\begin{array}{c}\text { Number of people taking } \\
\text { Undergraduate level ELA } \\
\text { course }\end{array}$ & $\begin{array}{c}\text { Number of people taking } \\
\text { Graduate level ELA } \\
\text { course }\end{array}$ & $\begin{array}{c}\text { Number of people taking } \\
\text { SEI }\end{array}$ \\
\hline 0 & 5 & 7 & 10 \\
\hline $1-3$ & 8 & 10 & 0 \\
\hline $4-6$ & 2 & 1 & 1 \\
\hline $7-9$ & 2 & 0 & 0 \\
\hline $10-$ more & 2 & 1 & 8 \\
\hline
\end{tabular}

\subsection{Data collection}

Creswell (2007) suggests that researchers "include data collection types that go beyond typical observations and interviews. These unusual forms create reader interest in a proposal and can capture useful information" (p. 184). In this study, data were collected through participants' written responses to two tasks; published-text (PT) and student-text (ST). For published-text, a K-5 children's book written in fictional narrative genre was used for participants to identify its genre and linguistic features. Fictional narrative genre was chosen because both teachers and K-5 students are highly familiar with it to be in the same genre as published text, a fictional narrative text written by a fourthgrade English-Spanish bilingual student was given to participants to identify the strengths and weaknesses of the text. Furthermore, despite teachers' and students' familiarity with fictional narrative, its genre- and language-related features are more complicated than thought due to linguistic and cognitive intricacies in creating and explaining the characters and events in the story.

At the beginning of the course, before different types of genres, their textual, as well as linguistic features, were introduced, participants completed the PT and ST analysis tasks in class. In the PT analysis task participants were asked: "if you were to use this text as a mentor text to teach writing, what features of the text they would use to teach the children." Each participant was given a copy of the book and a blank paper to write their comments. In the ST analysis task, participants were asked to "list the good aspects and problem areas in this student's writing. For specific problems, circle the problem on the text, assign a number to the circle, and write the number below. Next to the number please indicate what kind of problem it is." Each participant received a copy of the student text with a blank paper to write their comments. Both tasks were completed during the same class period and each task was given ten minutes to complete.

Before the semester ended, participants were asked to re-analyze the same PT and ST. In order to prevent participants' experiences in the pre-analysis interfere with their post-analysis, the post-analysis tasks were given eight weeks after the pre-analysis tasks. The prompts for post-analysis were the same as pre-analysis prompts. Each post-task was completed in 10 minutes during the same class period. 


\subsection{Data analysis}

Data collected from PT and ST tasks were analyzed through content analysis. A rubric developed by the course instructor was used to categorize the content. The rubric was informed by SFL and had a total of twenty SFL areas regarding language and genre which were grouped within Topic/Field, Tenor, and Mode. The SFL areas grouped within Topic/Field were: title, knowledge/topic, vocabulary, sentence structure, noun groups/types, verb groups, adverbials, and grammatical morphemes. The SFL areas grouped within Tenor were: audience, voice, and identity. The SFL areas grouped within Mode were: text structure-genre, text structure-medium, rhetorical links, theme, reference ties, lexical ties, ellipsis, substitution, spelling, capitalization, and punctuation. The rubric was utilized to note language- and genre-related areas that participants identified in both tasks at the beginning and end of the course. Individual rubrics were created for each participant and their comments were placed under appropriate categories in the rubric. For instance, the comment "descriptive words such as adjectives" was placed under the Noun Group category in the rubric. The comment "use of adverbials" was placed under Adverbials within the Topic/Field section.

Despite the easy categorization of some comments, some were difficult to categorize due to lack of specificity. When comments were too vague to categorize, they were not included in the analysis. For instance, the comment "grammar" could not be categorized, as grammar might range from adjective placement in a sentence to verb tense or even punctuation. Another common example of vague comments was "descriptive language." Despite its common use among educators, "descriptive language" is a very general statement for SFL because it may include adjectives, verbs, adverbs, sentence structures, or even transitive words. Some other vague comments that were not included in the data analysis were "show-not-tell," "sentence structure," "use of tense," and "features of the narrative."

Besides some vague comments, in some cases, the same comment made by different participants were categorized under different categories based on the meaning (context) of the comment. For instance, very common comment participants made was "dialogue." While in some contexts dialogue was placed under punctuation as it was used related to using quotation marks, in some instances, it was categorized under the audience in the rubric as it was used related to the voice of characters and making the story interesting for the readers. However, in some cases, the comment was solely "dialogue" without further explanation. In such cases, since it was not clear whether the response was mentioned related to punctuation, audience, or sentence structure, it was not categorized in the rubric.

\subsection{Validity and reliability}

Validity and reliability are essential parts of qualitative research studies. In order to address the validity of the study, I requested the course instructor, who is one of the leading researchers in the SFL field, to be a debrief investigator for the preparation of the tasks and the rubric (Guba \& Lincoln, 1982). In order to address the reliability, interrater reliability for data analysis was established (Holsti, 1969). A colleague, who had a doctoral degree in TESOL and a minor in linguistics, was requested to be the second coder of content analysis. Although there are various calculations for establishing interrater reliability (Neuendorf, 2016), in cases where two coders code the same cases, Holsti's interrater reliability calculation is recommended (Neuendorf, 2016). The formula for Holsti's interrater reliability is PAo $=2 \mathrm{~A} /\left(\mathrm{n}_{\mathrm{A}}+\mathrm{n}_{\mathrm{B}}\right)$, where PAo is the proportion of the agreement, $\mathrm{n}_{\mathrm{A}}$ and $\mathrm{n}_{\mathrm{B}}$ are the total number units coded by the two coders (Holsti, 1969). A conservative minimum interrater reliability of $85 \%$ was aimed to be achieved before coding of all units started (Miles \& Huberman, 1994).

Interrater reliability was calculated for a participant's pre-and post-analysis of PT (PT1 and PT2) and ST (ST1 and ST2). The initial interrater reliability percentages were $65 \%$ for PT1 and PT2, 60\% 
for ST1, and 40\% for ST2. In order to increase the interrater reliability, some adjustments were made for categorizing content. For instance, although some comments such as "narrative" were categorized within "text-structure genre", in the second reading, this comment was taken out of the analysis as there are various subtypes within the narrative genre. Since the participant did not mention specifically the fictional narrative genre as the type of text, vague comments such as "narrative" were excluded from the analysis on the account of being vague. Finally, some comments within a category were counted multiple times, if these comments addressed different features of that category. For instance, a participant commented on verbs but she mentioned it in terms of both tense (present past) and type (action verbs). In such cases, although the participant commented on verbs, her comments were noted twice for tense and type.

Multiple adjustments as described above were made to attain the minimum reliability percentages. Therefore, interrater reliability had to be calculated multiple times with randomly selected pre- and post-responses to PT and ST. Finally, the interrater reliability percentages were $90 \%$ for PT1, and $85 \%$ for PT2, ST1, and ST2.

\section{Results}

Findings related to the two research questions are reported separately in two sections. In each section, the frequency distribution of the SFL areas identified in pre-and post-tasks is presented as a table. This table gives a general view of the overall findings and the three sections included in the rubric; Topic/Field, Tenor, and Mode. Following the frequency distribution, representation of frequencies is given as a bar graph to visually report the results regarding each of the twenty categories in the rubric. Finally, excerpts from participants' original pre- and post-responses to the PT and ST are shown to offer a meaningful context to the findings.

\subsection{Findings on the analysis of the published text}

Table 2 shows that when PT1 and PT2 are compared, participants made more identifications of SFL areas in PT2. The total frequency for all of the SFL areas identified in PT2 $(f=60)$ was almost three times more than the areas identified in PT1 $(f=23)$.

Table 2. Frequency distribution of pre-and post-responses to published text in three categories

\begin{tabular}{|c|c|c|c|}
\hline & SFL areas & PT1 Frequency $(f)$ & PT2 Frequency $(f)$ \\
\hline \multirow{9}{*}{ Topic/Field } & Title & 0 & 0 \\
\hline & Knowledge/Topic & 0 & 0 \\
\hline & Vocabulary & 5 & 3 \\
\hline & Sentence Structure & 1 & 4 \\
\hline & Noun Groups/Types & 5 & 9 \\
\hline & Verb Groups & 1 & 4 \\
\hline & Adverbials & 1 & 8 \\
\hline & Grammatical morphemes & 0 & 0 \\
\hline & Total: & 13 & 28 \\
\hline \multirow{2}{*}{ Tenor } & Audience (Voice, identity) & 3 & 8 \\
\hline & Total: & 3 & 8 \\
\hline
\end{tabular}




\begin{tabular}{|l|l|c|c|}
\hline \multirow{5}{*}{} & Text structure-genre & 1 & 10 \\
\cline { 2 - 4 } & Text structure-medium & 0 & 0 \\
\cline { 2 - 4 } Mode & Rhetorical links & 2 & 0 \\
\cline { 2 - 4 } & Theme & 0 & 0 \\
\cline { 2 - 4 } & Reference ties & 0 & 0 \\
\cline { 2 - 4 } & Lexical ties & 0 & 0 \\
\cline { 2 - 4 } & Ellipsis & 0 & 0 \\
\cline { 2 - 4 } & Substitution & 0 & 1 \\
\cline { 2 - 4 } & Spelling & 0 & 0 \\
\cline { 2 - 4 } & Conventions: Capitalization & 0 & 6 \\
\cline { 2 - 4 } & Conventions: Punctuation & 4 & 24 \\
\cline { 2 - 4 } & & $\mathbf{2 3}$ & $\mathbf{6 0}$ \\
\hline
\end{tabular}

The frequency distribution above also illustrates that in their response to PT2, participants identified more SFL related areas, regarding Mode, followed by Topic/Field. In the Mode section of the rubric, participants made three times more comments in PT2 $(f=24)$ than PT1 $(f=7)$. As for the Topic/Field section, the total frequency of identifications of SFL areas was thirteen in PT1, but it increased to twenty-eight in PT2. Finally, in the Tenor section, the frequency of identified SFL areas increased from seven to twenty-four.

Following the general finding discussed above, Graph 1 below presents frequency distribution for all of the twenty SFL areas included in the rubric and allows us to see which specific SFL areas showed the largest difference between pre-and post-responses. As can be seen from the graph, participants did not comment on title, knowledge, grammatical morphemes, text structure-medium, theme, reference ties, lexical ties, ellipsis, substitution, and capitalization in PT1 and PT2. A decrease in the frequency of identification is observed only for vocabulary (PT1 $f=5$, PT2 $f=3$ ). Since SFL does not discuss about vocabulary, but the language in terms of function, a decrease in vocabulary is not surprising. The rest of all the other SFL areas indicate an increase in their frequency distribution for PT2. The highest difference in frequency is seen in text structure-genre (PT1 $f=1$, PT2 $f=10$ ) and adverbials (PT1 $f=1$, PT2 $f=8$ ). The frequency for the audience also increased from three to eight. Participants mentioned rhetorical links more frequently in PT2 $(f=7)$ than in PT1 $(f=2)$. Although not as sharp as in other SFL categories, the increase in frequencies of Noun Groups (PT1 $f=5$, PT2 $f=9$ ), Verb Groups (PT1 $f=1$, PT2 $f=4$ ), Sentence structure (PT1 $f=1$, PT $2 f=4$ ), Punctuation (PT1 $f=4$, PT2 $f=6$ ), and also Spelling (PT1 $f=0, \mathrm{PT} 2 f=1$ ) can be seen from the graph. 


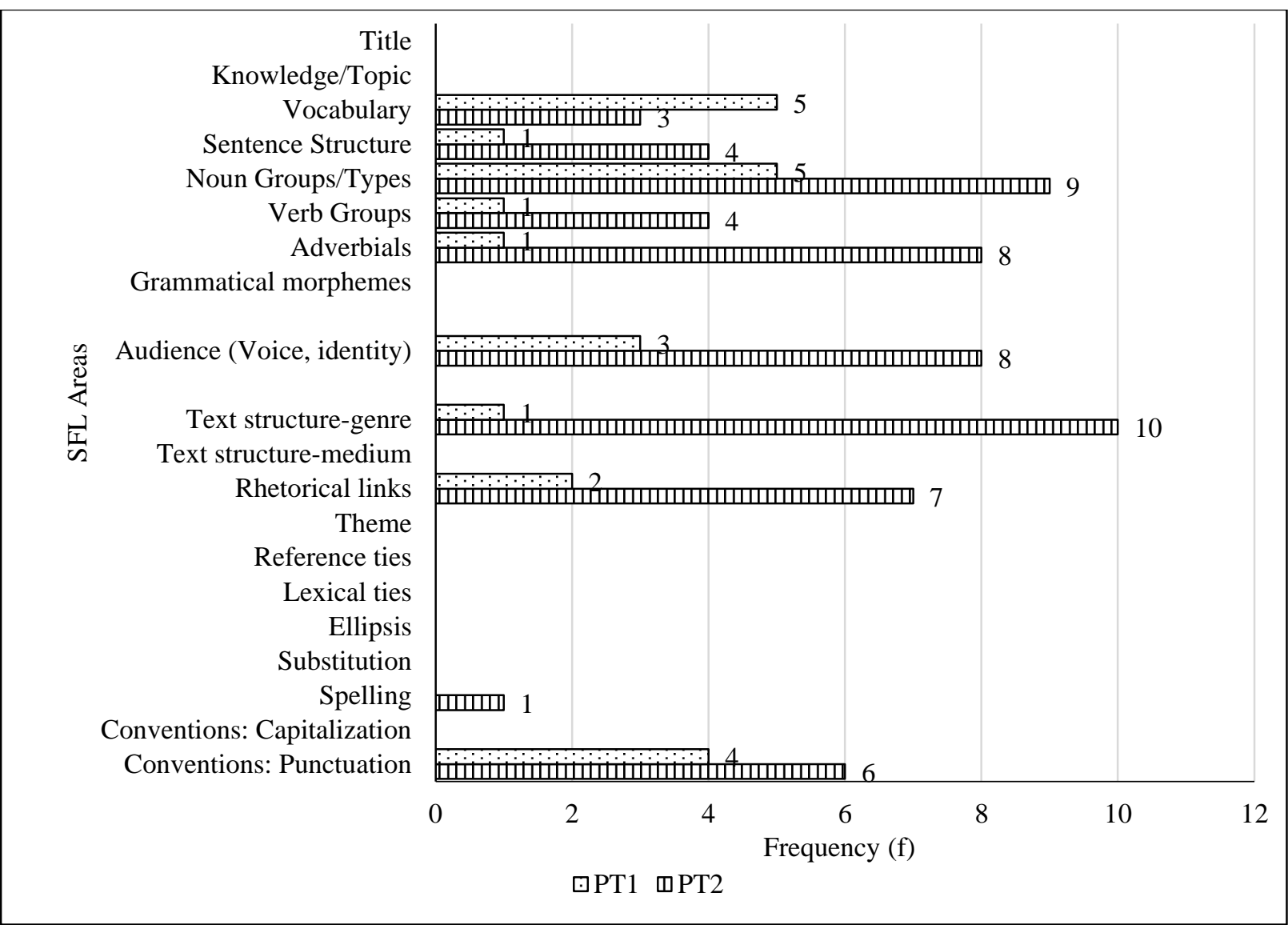

Graph 1. Frequency distribution of pre-and post-responses to the published text

To present the results in a more meaningful context, in the following part of the findings, original participant responses are shared. Table 3 depicts a participant's pre-and post-responses given to the published text. In his pre-response to PT, he mentioned using the book to teach mainly "characters" and "dialogue" so that they can "show" the story, "not just tell". However, he does not mention any linguistic tools for achieving this "show and not just tell".

Table 3. A participant's pre-and post-response to published text

\begin{tabular}{|l|l|}
\hline \multicolumn{1}{|c|}{ Response to PT1 } & \multicolumn{1}{c|}{ Response to PT2 } \\
\hline $\begin{array}{l}\text { I think I could use this to teach about characters. Using } \\
\text { dialogue, thoughts, and characters' actions to reveal } \\
\text { and/or reflect aspects of the story, rather than simply } \\
\text { stating them. In a sense, teaching them a little about } \\
\text { showing, and not just telling. }\end{array}$ & $\begin{array}{l}\text { Lists } \\
\text { Combining sentences- take a long sentence \& break it } \\
\text { into constituent parts. There are several long sentences } \\
\text { in the story. } \\
\text { Text connectives-then, at last, when, as, many years } \\
\text { after. } \\
\text { Dialogue- (third-person narration also) }\end{array}$ \\
& $\begin{array}{l}\text { Parts of speech- descriptive language - adjectives, } \\
\text { adverbs }\end{array}$ \\
Orientation- problem, resolution
\end{tabular}


Unlike his vague comments in PT1, in PT2 he made a list of things that were heavily related to language to achieve "show and not just tell". For instance, he mentioned using the book as an example to teach parts of speech and descriptive language, specifically adjectives, and adverbs. After taking the course, he seemed to realize that to teach how to "show", teachers need to teach and give examples of how to use adjectives and adverbs. Furthermore, he also mentioned using the book as an example to demonstrate how to make more complex sentences. He suggested taking a long sentence from the story and breaking it into smaller sentences so that students can realize how the author made a complex sentence by combining short sentences. Another language-focused comment was about using text connectives. He also made a post-comment about the genre-related feature of the text, which is using the book to teach about dialogue. Unlike many participants who mentioned dialogue in terms of teaching the correct use of quotation marks, he mentioned dialogue to teach how to express characters' thoughts and feelings in fictional narratives. Finally, he mentioned third person use, as in fictional genres stories are told in the third person.

To summarize, compared to his PT1, this participant's responses to PT2 were more language and genre-specific. His genre and language knowledge specific to fictional narrative seems to help him express more specific and better-defined writing tools to teach about "show and not just tell" in his PT2.

The graph presented earlier indicated that the most change occurred in the text structure-genre area of the rubric. The excerpt given in Table 4 provides a meaningful context depicting this change. When the PT1 and PT2 responses are compared, it is clear that this participant had some change in her knowledge about the genre.

Table 4. A participant's pre-and post-response to published text

\begin{tabular}{|c|c|}
\hline Response to PT1 & Response to PT2 \\
\hline $\begin{array}{l}\text { I would teach about the genre of the personal recount, } \\
\text { making sure to emphasize detail, so that the student } \\
\text { understands that it helps the reader picture the story if } \\
\text { there were no pictures. }\end{array}$ & $\begin{array}{l}\text { - Fictional narrative genre } \\
\text { - } \quad \text { Passage of time (on the } 6^{\text {th }} \text { of Sept., day and } \\
\text { night, etc.) } \\
\text { - Use of adverbs to strengthen story (in the } \\
\text { middle of the immense ocean, quickly, into the air, } \\
\text { etc.) }\end{array}$ \\
\hline $\begin{array}{l}\text { Secondly, I would point out how the story transitions } \\
\text { from the character's inner thoughts to external verbal } \\
\text { conversations. }\end{array}$ & $\begin{array}{l}\text { - } \quad \text { Beginning, middle \& end of story } \\
-\quad \text { Audience (who would be more likely to read } \\
\text { this type of story) }\end{array}$ \\
\hline
\end{tabular}

In her PT1, the participant identified the genre of the published text wrong. Although the text was a fictional narrative, she stated it as a personal recount. However, she identified the genre correctly in her PT2. Furthermore, by mentioning using the text to teach a passage of time and adverbs, she also seemed to show some change in her knowledge regarding language and aspects of language that could help students write more descriptively. When she mentioned "passage of time," the participant actually meant adverbials of time, which shows that although she does not have the metalanguage, she understood the linguistic function.

Another example that clearly illustrates the increased knowledge about the genre is the number of correct identifications of the book's genre in PT2. Overall, ten people correctly identified the genre of the book in PT2, while only one participant identified it correctly in PT1. Although some participants did not clearly mention the name of the genre as a fictional narrative in PT2, through discussing fictional narrative features such as climax and resolution they showed their awareness about the genre of the book. Furthermore, analysis of participant responses indicated that while most PT1 responses 
discussed using the text as a response to literature, PT2 responses were specific to genre and language that could help teaching about how to add details to the story. For instance, in PT1 responses, some participants mentioned using the book to give a writing assignment for; writing about planktons, ocean, mammals (report genre), explanation on the ocean (explanation genre), how to make a boat (procedure genre), adventure recounts (personal recount genre). However, these stated genres were all different from the published text's genre and required different use of text structure and language features. After the course, participants began to give tasks more specific to and appropriate for fictional narrative and its linguistic features. For instance, to name a few, they started using the book as a model to teach how to write climax and resolution parts of the story, sequence of events, or using the third person.

The published-text findings can be summarized as the improvement in participants' awareness about genre and language at the end of the course. At the end of the course, participants started to identify teachable aspects that were parallel to the book's genre and linguistic content, rather than responding to the morals and lessons of the story. This change in identifying teachable aspects that are parallel to the book's genre and content indicates that participants began utilizing the book as a model for writing instruction, rather than as literature to respond.

\subsection{Findings on the analysis of the student text}

The frequency distribution of participants' pre-and post-responses to student-text was created to give a general idea about whether there was a difference in their identification of the SFL areas. Table 5 shows that when ST1 and ST2 are compared, the total frequency for all SFL areas identified in ST2 $(f=80)$ is higher than ST1 $(f=63)$. This indicates that by the end of the course participants showed higher awareness of genre and language.

Table 5. Frequencies of pre-and post-responses to student text in three categories

\begin{tabular}{|c|c|c|c|}
\hline & SFL areas & PT1 Frequency $(f)$ & PT2 Frequency $(f)$ \\
\hline \multirow{9}{*}{ Topic/Field } & Title & 0 & 0 \\
\hline & Knowledge/Topic & 0 & 0 \\
\hline & Vocabulary & 5 & 3 \\
\hline & Sentence Structure & 1 & 4 \\
\hline & Noun Groups/Types & 5 & 9 \\
\hline & Verb Groups & 1 & 4 \\
\hline & Adverbials & 1 & 8 \\
\hline & Grammatical morphemes & 0 & 0 \\
\hline & Total: & 13 & 28 \\
\hline \multirow{2}{*}{ Tenor } & Audience (Voice, identity) & 3 & 8 \\
\hline & Total: & 3 & 8 \\
\hline \multirow{5}{*}{ Mode } & Text structure-genre & 1 & 10 \\
\hline & \begin{tabular}{|l|} 
Text structure-medium \\
\end{tabular} & 0 & 0 \\
\hline & Rhetorical links & 2 & 7 \\
\hline & \begin{tabular}{|l|} 
Theme \\
\end{tabular} & 0 & 0 \\
\hline & \begin{tabular}{|l|} 
Reference ties \\
\end{tabular} & 0 & 0 \\
\hline
\end{tabular}




\begin{tabular}{|l|l|c|c|}
\hline \multirow{4}{*}{} & Lexical ties & 0 & 0 \\
\cline { 2 - 4 } & Ellipsis & 0 & 0 \\
\cline { 2 - 4 } & Substitution & 0 & 0 \\
\cline { 2 - 4 } & Spelling & 0 & 1 \\
\cline { 2 - 4 } & Conventions: Capitalization & 0 & 0 \\
\cline { 2 - 4 } & Conventions: Punctuation & 4 & 6 \\
\cline { 2 - 4 } & & 7 & 24 \\
\hline Total frequency of SFL Areas identified: & $\mathbf{2 3}$ & $\mathbf{6 0}$ \\
\hline
\end{tabular}

When Topic/Field, Tenor, and Mode are compared, it is observed that there is not much change in the Topic/Field and Tenor sections for ST1 and ST2. The total frequency of SFL areas for Topic/Field was thirteen in ST1 and fourteen in ST2. As for Tenor, there is a decrease in frequency from six in ST1 to four in ST2. The largest difference in frequency distribution is observed in the Mode section, which focuses on the cohesion of a text (ST1 $f=44$ versus ST2 $f=62$ ).

Following the general findings discussed above, Graph 2 below presents frequency distribution for all of the twenty SFL areas included in the rubric and allows us to see which specific SFL areas showed the largest difference between pre-and post-responses.

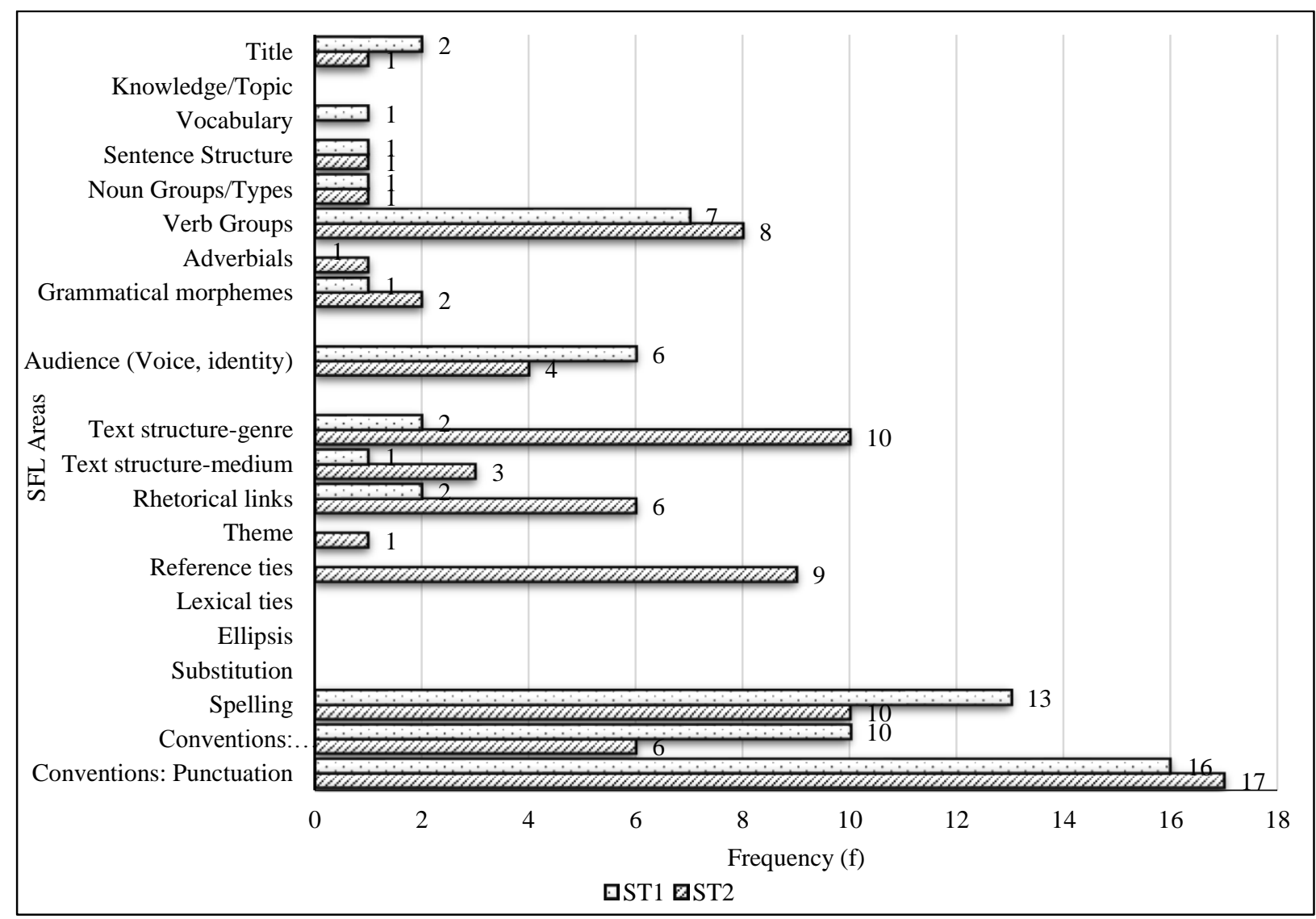

Graph 2. Frequency distribution of pre-and post-responses to student text

As the graph demonstrates, participants did not comment on knowledge, lexical ties, ellipsis, and substitution in ST1 and ST2. The frequencies of sentence structure and noun groups the same both for 
ST1 $(f=1)$ and ST2 $(f=1)$. A decrease in frequency of identification is observed for title (ST1 $f=2$, ST2 $f=1$ ), vocabulary (ST1 $f=1, \operatorname{ST} 2 f=0$ ), audience (ST1 $f=6$, ST2 $f=4$ ), spelling (ST1 $f=13$, ST2 $f=10$ ), and capitalization (ST1 $f=10$, ST2 $f=6$ ). The largest decreases in frequencies are in capitalization and spelling respectively. The rest of all the other SFL areas indicate an increase in their frequency distribution for ST2. The largest increase is seen in reference ties (ST1 $f=0$, ST2 $f=9$ ) and text structure-genre (ST1 $f=2$, ST2 $f=10$ ). Although the difference is not as sharp as reference ties and genre area, there is also an increase in frequencies of rhetorical links (ST1 $f=2$, ST2 $f=6$ ), verb groups (ST1 $f=7$, ST2 $f=8$ ), adverbials (ST1 $f=0$, ST2 $f=1$ ), grammatical morphemes (ST1 $f=1$, ST $2 f=2$ ), text structure-medium (ST1 $f=4$, ST2 $f=3$ ), theme (ST1 $f=0$, ST2 $f=1$ ), and punctuation (ST1 $f=16$, ST2 $f=17)$.

These results indicate that, by the end of the course, participants commented less on what teachers commonly name as mechanics of writing such as capitalization and spelling, but they commented more on SFL areas that focus on cohesion, meaning, and language features. To provide a meaningful context for the results presented through Table 5 and Graph 2, excerpts from participants' original preand post-responses to ST are presented below. Similar to the published-text findings, the excerpt in Table 6 illustrates the change in a participant's knowledge about the genre as well as language.

Table 6. A participant's pre-and post-response to student text

\begin{tabular}{|c|c|}
\hline Response to ST1 & Response to ST2 \\
\hline $\begin{array}{l}\text { Good Aspects } \\
\text { Title (proper noun in a text also) } \\
\text { - } \quad \text { Using quotations when someone is } \\
\text { speaking } \\
-\quad \text { Great storyteller! } \\
-\quad \text { Creative character names } \\
\text { Problem Areas } \\
-\quad \text { Wasn't (contractions not used correctly) } \\
-\quad \text { Sentence structure } \\
-\quad \text { Use of punctuation } \\
-\quad \text { Abb. Omg \& tonite }\end{array}$ & $\begin{array}{l}\text { Good Aspects } \\
\text { Text structure- clear beginning, middle \& end, which } \\
\text { is the correct form for a fictional narrative. } \\
\text { Conflict is resolved throughout the story. } \\
\text { Sentence structure- She has a clear thought process in } \\
\text { her sentences- sometimes difficult to understand } \\
\text { Problem Areas } \\
\text { Theme \& Rheme- There is no clear Theme \& Rheme } \\
\text { throughout the story. At points, she loses the readers' } \\
\text { attention. } \\
\text { The use of quotations is hard to follow } \\
\text { Text connectives are missing throughout } \\
\text { Spelling } \\
\text { Nouns are hard to follow who she is talking about }\end{array}$ \\
\hline
\end{tabular}

In ST1, the participant commented on title, character names, use of quotation, punctuation, and contractions as well as sentence structure. There is not any comment specific to the fictional narrative or the linguistic features of the genre. Although sentence structure is related to language, it is vague. On the other hand, in ST2 the participant specifically named the genre as fictional narrative. Also, she commented on the text structure of this specific genre by mentioning the conflict and its resolution in the story. Related to language, she commented on more language-specific areas such as nouns (she means reference ties), text connectives, and theme and rheme. Similar to ST1, she commented on sentence structure in ST2. Although she mentioned it in a vague manner under the problem area in ST1, in her post-comment, she commented on sentence structure as "sometimes difficult to understand", and in the problems areas she mentioned some reasons that explained the difficulty, such 
as the issues in the use of theme and rheme, nouns (reference ties), text connectives, and quotations. In other words, her comment in ST2 about sentence structure was more language-specific.

Another excerpt is given in Table 7 to explain how a participant's knowledge about language changed at the end of the course.

Table 7. A participant's pre-and post-response to student text

\begin{tabular}{|c|c|}
\hline Response to ST1 & Response to ST2 \\
\hline Good Aspects & Good Aspects \\
\hline $\begin{array}{l}\text { Aware of an organization- knows there should be a } \\
\text { beginning, middle, and end }\end{array}$ & $\begin{array}{l}\text { Organization- knows there are beginnings, } \\
\text { middles, ends }\end{array}$ \\
\hline $\begin{array}{l}\text { About to write a large amount of volume on a particular } \\
\text { topic }\end{array}$ & $\begin{array}{l}\text { Use/Willingness to use dialogue to enhance the } \\
\text { story }\end{array}$ \\
\hline Includes imaginative voice/emotions & Uses some sequencing words like "then" \\
\hline Includes a clear plot (organization) & Creative idea- the author knows that she/he is \\
\hline Attempting to include dialogue and a variety of sentence & trying to say \\
\hline structure & Some vocabulary- ex. Naive, goslings, frustrated \\
\hline Problem Areas & Problem Areas \\
\hline Capitalization - she capitalizes words that should not be. & Uses casual terms like "OMG" \\
\hline Contractions & Adverbs- misuses \\
\hline \multirow{6}{*}{$\begin{array}{l}\text { Use of quotations - sometimes she uses them correctly, } \\
\text { mostly she uses incorrectly or omits them } \\
\text { Spelling- could be an indication of editing uses "omg" } \\
\text { (Oh my God)- may be a problem depending on purpose } \\
\text { and audience of writing }\end{array}$} & Capitalization \\
\hline & Lots of confusing pronouns- $\mathrm{He}$, she, he, she \\
\hline & Needs punctuation to enhance clarity \\
\hline & Doesn't need "the end" \\
\hline & $\begin{array}{l}\text { Who is the audience? - How would this change } \\
\text { her/his writing }\end{array}$ \\
\hline & Character development \\
\hline
\end{tabular}

A striking difference can be seen in the "problems areas" sections in ST1 and ST2. In her comments for problem areas in ST1, the participant solely focused on the mechanics of writing; capitalization, contractions, quotations, and spelling. However, in ST2, she commented on sequencing words (rhetorical links), adverbs, and pronoun (reference ties). Specifically related to pronouns, one of the SFL areas showing the most increase in the frequency Table 5 was reference ties. In their preresponses to ST, many participants mentioned pronouns to explain the student error in capitalization. However, in their post-responses, participants identified pronouns more related to the problems they caused in meaning and comprehension, rather than capitalization. Similar to this general finding, in the excerpt above, the participant mentioned in her ST1 that the student capitalized words that should not be capitalized, which are pronouns. However, in her second response, she mentioned pronouns for the confusion they created in understanding, not capitalization or spelling.

Besides her language-related comments, by mentioning character development, she also made a genre-related comment. In the fictional narrative, character development is the most essential step of creating the story. By commenting on character development as a problem area in the ST2, the participant shows that she is more aware of the requirements of the genre. 
Shortly, while participants' comments in ST1 were mostly related to mechanics of writing such as capitalization and punctuation, responses in ST2 were more informed about genre and language. Therefore, the decrease in the frequency of spelling and capitalization, as illustrated in Graph 2, is not surprising.

As the conclusion of findings, Graph 3 summarizes the pre-and post-responses to PT to ST in terms of the three SFL sections in the rubric; Topic/Field, Tenor, and Mode. The graph depicts that for PT, participants identified more SFL areas in post-analysis for both Topic/Field and Mode. However, for ST, participants identified more SFL areas in post-analysis only for Mode.

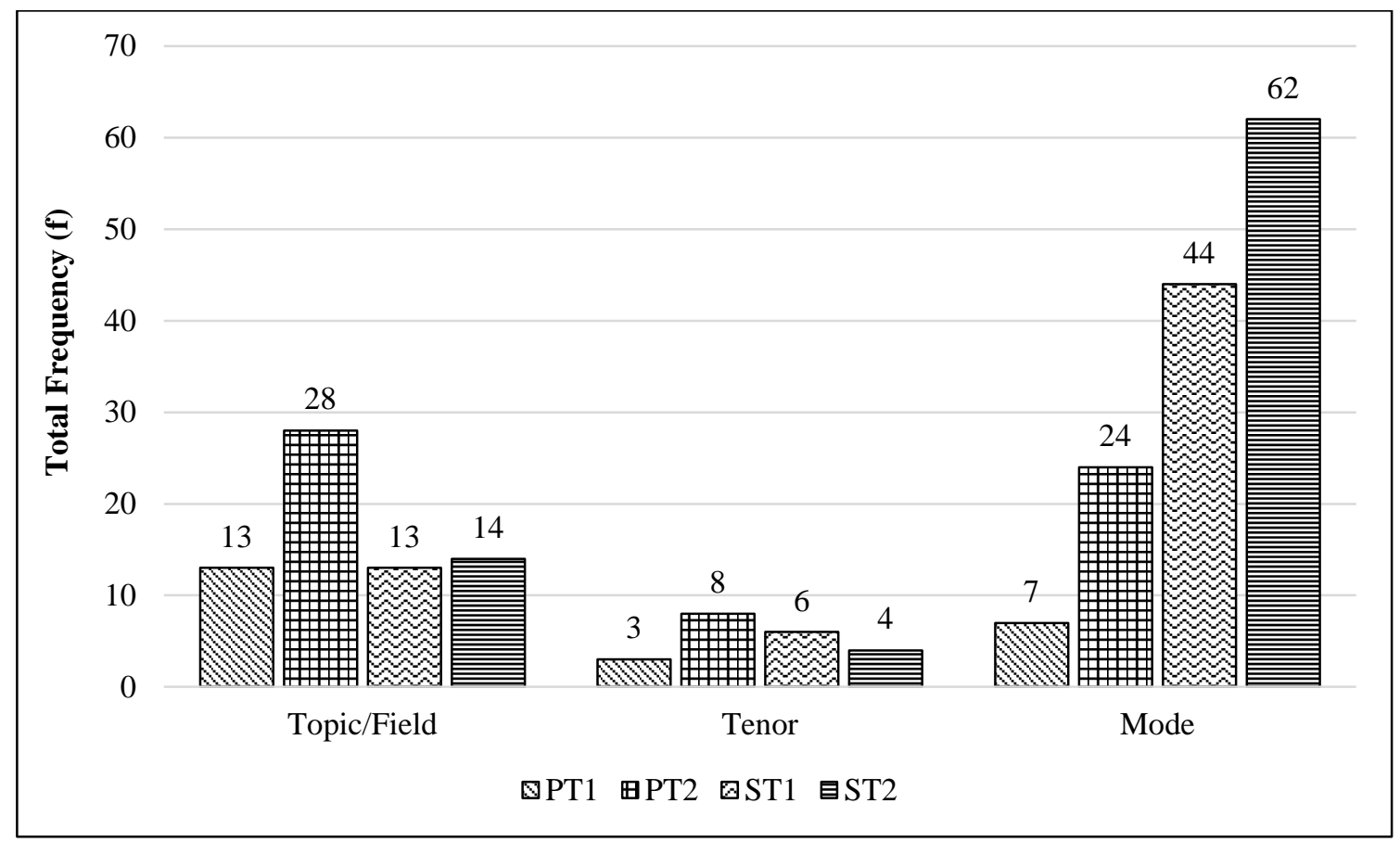

Graph 3. Frequency distribution of pre-and post-responses to published text and student text in three categories

Regarding Topic/Field, while the frequencies for PT1 $(f=13)$, ST1 $(f=13)$, and ST2 $(f=14)$ are very close to each other, there is a large difference in frequency of Topic for PT2 $(f=28)$. Regarding Tenor, the frequencies for all responses for both tasks are close to each other. However, compared to PT1 $(f=3)$, ST1 $(f=6)$, and ST2 $(f=4)$, the tenor-related SFL area (audience, voice, identity) is mentioned the most in PT2 $(f=8)$. The largest change in frequencies is observed in Mode for both the PT and ST. At the end of the course, with their increased knowledge in genre and language, participants made more comments on SFL areas specifically on the genre, rhetorical links, and reference ties in both PT and ST. Interestingly, participants identified more Mode (cohesion) related items for ST compared to PT even in pre-responses.

\section{Discussion and conclusions}

This article explored whether teacher candidates analyzed published text and student text written in the fictional narrative genre differently after receiving SFL informed instruction to teach writing in elementary grades. After receiving a semester-long course offered through the lens of SFL, findings for analyses of both published and student texts indicated an increased awareness of the fictional narrative genre and the linguistic features it requires. These findings are consistent with extant research which indicate heightened awareness and understanding of school texts and their language features in 
teachers (Accurso, Gebhard, \& Selden, 2016; Achugar \& Carpenter, 2012; Brisk, Hodgson-Drysdale, \& O’Connor, 2010; Brisk \& Zisselsberger, 2011; Fang, Sun, Chiu, \& Trutschel, 2014; Gebhard, Habana Hafner, \& Wright, 2004; O’Hallaron, Palincsar, \& Schleppegrell, 2015).

Among the changes across analysis of both published and student text, use of more specific metalanguage stands out. In the comments made before the course, participants used vague terms such as "detail", "beginning, middle, end", and "show and not tell" to name a few. Whereas after the course they were more specific naming the stages of the genre (orientation, climax, resolution) and language (adverbials, adjectives). Sometimes participants named the function, such as "passage of time" rather than an aspect of language, such as adverbials of time or "sequencing words" rather than rhetorical links. Although participants did not use metalanguage to the fullest potential, they had the notion that language has a function. This finding is similar to what Slater and McCrocklin (2016) found after analyzing data from nine teachers who completed only a 2-hour workshop that focused on metalanguage for unpacking meaning in children's storybooks. Their study illustrated that even short workshops were successful at heightening teachers' semiotic awareness. However, they suggested offering longer workshops for teachers to build more confidence in using metalanguage because many teachers find metalanguage initially intimidating and challenging (Aguirre-Muñoz et al., 2008; Carpenter, Achugar, Walter, \& Earhart, 2015; Fang et al., 2014; Gebhard, Chen, Graham, \& Gunawan 2013; Schall-Leckrone \& McQuillan, 2012).

As for the separate discussions of published and student texts, a closer analysis of PT indicated that, at the beginning of the course, participants considered it as having the function of giving information to a reader and teaching how to respond to literature. Participants even commented on assigning students writing tasks that were in genres different from the fictional narrative. However, during the course, participants learned more about the fictional narrative genre and language. Being more informed about the genre and its linguistic features, at the end of the course, participants began to consider using it as a mentor text to teach how the writer constructs the fictional narrative genre and the specific features of language as well as their function.

Closer analysis of ST indicated that after the course participants learned to see the issues of children's writing beyond mechanics. This change in lesser attention given to mechanics reflected itself in mainly two ways: pronouns (reference ties) and dialogue. Before the class, most participants mentioned reference ties as an issue in student writing because the student capitalized them. However, after the course, participants commented on reference ties due to the lack of clear connection between the pronouns and the referent, which greatly hindered comprehension and caused confusion in meaning. As for the dialogue, at the beginning of the course participants mentioned it for teaching how to use quotation marks correctly. However, at the end of the course, they began considering dialogues as a feature of the fictional narrative genre through which characters of the story express their thoughts and feelings.

Along with the change in the purpose of mentioning reference ties and dialogues, the decrease in frequencies of capitalization and spelling in post-analysis of student text also confirms the conclusion about how participants' approach to issues of children's writing changed from mechanics to meaning. Teachers consider responding to student errors in writing as a vital part of their job (Ferris, 1995) However when they focus too much on students' errors in writing, "there is less time for feedback on other perhaps more important aspects of writing such as content coherence" (Lee, 2005, p. 2) Focusing too much on formal correctness than to the discourse level of writing may cause students to believe that formal accuracy such as grammar and mechanics is more important than the meaning, overall organization, content development and coherence (Hedgcock \& Lefkowitz, 1996). Therefore, "selective error correction in which attention is given to specific error patterns rather than all errors" is suggested (Lee, 2005, p. 2). As suggested by Lee (2005) and documented by extant research on SFL- 
informed writing instruction and professional development, participants in this study became more selective of their feedback, began to diagnose the student's needs beyond spelling, punctuation, and vocabulary problems, and gave feedback related to genre and discourse expectations (Achugar, Schleppegrell, \& Oteíza, 2007; Aguirre-Muñoz et al., 2008; Brisk \& Zisselsberger, 2011).

To conclude, this study used the SFL as a lens to explore the features of narratives, in particular fictional narratives, to provide teacher candidates the knowledge about the genre and language it requires. Results showed that even though it was a semester-long SFL informed instruction, teacher candidates become better aware of what to teach when teaching writing. "SFL provides teachers the knowledge of how a culture constructs genre and how register variables (topic, audience and voice, and written mode) guide language choices to construct intended meaning." (Brisk et al., 2021, p. 11). Written language is different from oral language (Halliday, 1989) and students' best source for learning a written language is the written texts they encounter (Brisk et al., 2021). After the course, participants began to use the published texts as a model to teach the targeted genre's structural and linguistic features. From these texts, they identified what ELLs can incorporate into their own writing (Gebhard, Harman, \& Seger, 2007). However, further research is needed if once acquired teacher candidates transfer it to instruction. Therefore, there is a need for longitudinal studies that integrate observations as data collection tools to observe teacher practices. There is also a need for more research in different teacher-education contexts, such as Arslan's (2013) study which investigated the teaching of various genres to prospective teachers of English in the Turkish context, where writing skills in English is relatively weak due to the educational focus given to the learning of English grammar and vocabulary.

\section{Ethics Committee Approval}

The authors confirm that this study does not need ethics committee approval.

\section{Acknowledgments}

I would like to give my gratitude to Prof. Maria Estella Brisk for the valuable time and input she provided to this manuscript. She consented to data collection from her course. She shared her immense knowledge in SFL and vast experiences in research with me throughout the study.

\section{References}

Accurso, K., Gebhard, M., \& Selden, C. (2016). Supporting L2 elementary science writing with SFL in an age of school reform. In de Oliveira \& T. Silva (Eds.), Second language writing in elementary classrooms: Instructional issues, content-area writing, and teacher education (pp. 126150). New York, NY: Palgrave Macmillan.

Achugar, M., \& Carpenter, B. D. (2012). Developing disciplinary literacy in a multilingual history classroom. Linguistics and Education, 23(3), 262-276. https://doi.org/10.1016/j.linged.2012.05.003

Achugar, M., Schleppegrell, M., \& Oteíza, T. (2007). Engaging teachers in language analysis: A functional linguistics approach to reflective literacy. English Teaching: Practice and Critique, 6(2), 8-24.

Aguirre-Muñoz, Z., Park, J., Amabisca, A., \& Boscardin, C. K. (2008). Developing teacher capacity for serving ELLs' writing instructional needs: A case for systemic functional linguistics. Bilingual Research Journal, 31(1-2), 295-322. https://doi.org/10.1080/15235880802640755 
Arslan, R. Ş. (2013). Integrated approach to enhancing prospective English language teachers' writing skills. Journal of Language and Linguistic Studies, 9(2), 1-17.

Brisk, M. E. (2015). Engaging students in academic literacies: Genre-based pedagogy in K-5 classrooms. New York, NY: Routledge.

Brisk, M. E., Tian, Z., \& Ballard, E. (2021). Autobiography writing instruction: The journey of a teacher participating in a systemic functional linguistics genre pedagogy professional development. The system, 97, 1-13. https://doi.org/10.1016/j.system.2020.102429

Brisk, M. E., Hodgson-Drysdale, T., \& O'Connor, C. (2010). A study of a collaborative instructional project informed by systemic functional linguistic theory: Report writing in elementary grades. Journal of Education, 191(1), 1-12.

Brisk, M. E., \& Zisselsberger, M. (2011). "We've let them in on the secret": Using SFL theory to improve the teaching of writing to bilingual learners. In T. Lucas (Ed.), Teacher preparation for linguistically diverse classrooms: A resource for teacher educators (pp. 111-126). New York: Routledge.

Carpenter, B. D., Achugar, M., Walter, D., \& Earhart, M. (2015). Developing teachers' critical language awareness: A case study of guided participation. Linguistics and Education, 32, 82-97. https://doi.org/10.1016/j.linged.2015.03.016

Christie, F. (1999). Genre theory and ESL teaching: A systemic functional perspective. TESOL Quarterly, 33(4), 759-763. https://doi.org/10.2307/3587889

Creswell, J. W. (2007). Qualitative inquiry and research design: Choosing among five approaches (2 ${ }^{\text {nd }}$ ed.). Thousand Oaks, CA: Sage.

Derewianka, B. (1990). Exploring how texts work. Rozelle, NSW, Australia: Primary English Teaching Association.

Fang, Z., Sun, Y., Chiu, C. C., \& Trutschel, B. K. (2014). Inservice teachers' perception of a languagebased approach to content area reading. Australian Journal of Language and Literacy, 37(1), 5566.

Ferris, D. R. (1995). Student reactions to teacher response in multiple-draft composition classrooms. TESOL Quarterly, 29(1), 33-53. https://doi.org/10.2307/3587804

Gebhard, M., Chen, I., Graham, H., \& Gunawan, W. (2013). Teaching to mean, writing to mean: SFL,

L2 literacy, and teacher education. Journal of Second Language Writing, 22(2), 107-124. https://doi.org/10.1016/j.jslw.2013.03.005

Gebhard, M., Habana Hafner, A., \& Wright, M. (2004). Teaching English language learners the language game of math. In M. Sadowski (Ed.), Teaching immigrant and second-language learners (pp. 33-46). Cambridge, MA: Harvard Educational Publishing Group.

Gebhard, M., Harman, R., \& Seger, W. (2007). Reclaiming Recess: Learning the language of persuasion. Language Arts, 84(5), 419-430.

Gibbons, P. (2002). Scaffolding language, scaffolding learning: Teaching second language learners in the mainstream classroom. Portsmouth, $\mathrm{NH}$ : Heinemann.

Gibbons, P. (2003). Mediating language learning: Teachers interactions with ESL students in a content-based classroom. TESOL Quarterly, 37(2), 247-273. https://doi.org/10.2307/3588504 
Goldenberg, C. (2008). Teaching English language learners: What the research does- and does not-say. American Educator, 32(2), 8-18.

Guba, E. G., \& Lincoln, Y. S. (1982). Epistemological and methodological bases of naturalistic inquiry. Educational Communication \& Technology Journal, 30(4), 233-252.

Halliday, M. A. K. (1978). Language as social semiotic: The social interpretation of language and meaning. Baltimore, WA: University Park Press.

Halliday, M. A. K. (1989). Spoken and written language. Oxford: Oxford University Press.

Halliday, M. A. K. (1994). An introduction to functional grammar. New York, NY: Routledge, Chapman and Hall, Inc.

Halliday, M. A. K., \& Matthiessen, C. M. I. M. (2004). An introduction to functional grammar ( $3^{\text {rd }}$ ed.). London: Hodder Arnold.

Hedgcock, J., \& Lefkowitz, N. (1996). Some input on input: Two analyses of student response to expert feedback in L2 writing. Modern Language Journal, 80(3), 287-308.

Herrera, S. G., \& Murry, K. G. (2005). Mastering ESL and bilingual methods: differentiated instruction for culturally and linguistically diverse (CLD) students. Boston, MA: Pearson Allyn and Bacon.

Holsti, O. R. (1969). Content analysis for the social sciences and humanities. Reading, MA: Addison Wesley.

Kress, G. (1989). Linguistic Processes in Sociocultural Practice. Oxford: Oxford University.

Labov, W., \& Waletsky, J. (1967). Narrative analysis. In J. Helm (Ed.), Essays on the verbal and visual arts (pp. 12-44). Seattle, WA: University of Washington Press.

Lee, I. (2005). Error Correction in the L2 Writing Classroom: What Do Students Think? TESL Canada Journal, 22(2), 1-16. https://doi.org/10.18806/tesl.v22i2.84

Martin, J. R., \& Rose, D. (2008). Genre relations: Mapping culture. Oakville, CT: Equinox.

Martin, J., \& Rothery, J. (1986). What a functional approach to the writing task can show teachers about "good writing". In B. Couture (Ed.), Functional approaches to writing: Research perspectives (pp. 241-265). Norwood, NJ: Ablex Publishing Corporation.

Martin, J. R., \& Veel, R. (1998). Reading science: Critical and functional perspectives on discourses of science. New York, NY: Routledge.

McKenough, A. (2013). A developmental approach to teaching narrative composition. In S. Graham, C. A. MacArthur, \& J. Fitzgerald (Eds.), Best practices in writing instruction (2 ${ }^{\text {nd }}$ ed., pp. 73-112). New York, NY: Guilford.

Merriam, S. B. (1998). Qualitative research and case study applications in education. San Francisco, CA: Jossey-Bass.

Miles, M., \& Huberman, A. (1994). Qualitative data analysis: A sourcebook. Thousand Oaks, CA: Sage.

Neuendorf, K. A. (2016). The content analysis guidebook. Thousand Oaks, CA: Sage.

O’Hallaron, C. L., Palincsar, A. S., \& Schleppegrell, M. J. (2015). Reading science: Using systemic functional linguistics to support critical language awareness. Linguistics and Education, 32, 55-67. https://doi.org/10.1016/j.linged.2015.02.002 
Rog, L. J., \& Kropp, P. (2004). The write genre. Markham, ONT, Canada: Pembroke.

Rose, D., \& Martin, J. R. (2012). Learning to write, reading to learn: Genre, knowledge, and pedagogy in the Sydney School. Sheffield: Equinox.

Roser, N., Martinez, M., Fuhrken, C., \& McDonnold, K. (2007). Characters as guides to meaning. The Reading Teacher, 60(6), 548-559.

Schall-Leckrone, L., \& McQuillan, P. J. (2012). Preparing history teachers to work with English learners through a focus on the academic language of historical analysis. Journal of English for Academic Purposes, 11(3), 246-266. https://doi.org/10.1016/j.jeap.2012.05.001

Schleppegrell, M. J. (2004). The language of schooling: A functional linguistics perspective. Mahwah, NJ: Lawrence Erlbaum.

Schleppegrell, M., Achugar, M., \& Oteíza, T. (2004). The grammar of history: Enhancing contentbased instruction through a functional focus on language. TESOL Quarterly, 38(1), 67-93. https://doi.org/10.2307/3588259

Schleppegrell, M. J., \& Go, A. (2007). Analyzing the writing of English learners: A functional approach. Language Arts, 84(6), 529-538.

Scott, N. (2015). Academic Writing and Culture: A Study of Austrian Tertiary-Level EFL Learners. AAA:Arbeiten Aus Anglistik Und Amerikanistik, 40(1/2), 75-97.

Siepmann, D. (2006). Academic Writing and Culture: An Overview of Differences between English, French and German. Meta, 51(1), 131-150. https://doi.org/10.7202/012998ar

Slater, T., \& McCrocklin, S. (2016). Learning to use systemic functional linguistics to teach literary analysis: Views on the effectiveness of a short professional development workshop. In L. C. de Oliveira \& M. Shoffner, Teaching English Language Arts to English Language Learners (pp. 19214). London: Palgrave Macmillan.

Yang, L., \& Cahill, D. (2008). The Rhetorical Organization of Chinese and American students' Expository Essays: A Contrastive Rhetoric Study. International Journal of English Studies, 8(2), 113-132.

Yin, R. K. (2014). Case Study Research Design and Methods (5th ed.). Thousand Oaks, CA: Sage.

\section{AUTHOR BIODATA}

Dr. Güliz Turgut Dost works as an assistant professor at English Language Teaching Department at Aydın Adnan Menderes University. She completed her BA at Boğaziçi University. She attained her MEd. and Ph.D. with specialization in Language, Literacy, and Culture from Boston College, Massachusetts USA. 